\title{
Occurrence of hard coral (Genus Montipora) common in Elphinstone Island and its adjacent areas of Myeik Archipelago, Myanmar
}

\begin{abstract}
A total 7 species of Montipora of the Family Acroporidae were recorded as dominated corals population in the present study area. The highest number of coral species ( 4 species) was found at Taung Pan Gyi Station. Montipora digitata and M patula are occurred at only Sha Aw. Moreover, M. floweri was also occurred at only The Hnit Tan.
\end{abstract}

Keywords: hard coral, Acroporidae, Montipora, identification, species composition
Volume 8 Issue I - 2019

\section{Zarni Ko Ko,' Khin Myo Myo Tint, ${ }^{2}$ Naung Naung $\mathrm{Oo}^{3}$}

'Assistant Lecturer, Department of Marine Science, Mawlamyine University, Myanmar

${ }^{2}$ Demonstrator, Department of Marine Science, Mawlamyine University, Myanmar

${ }^{3}$ Assistant Lecturer, Department of Marine Science, Mawlamyine University, Myanmar

Correspondence: Zarni Ko Ko, Department of Marine Science, Mawlamyine University, Myanmar.

Email znil446@gmail.com

Received: February 08, 2019 | Published: February 25, 2019

\section{Introduction}

Corals are primitive animals belonging to the Phylum Coelenterata or Cnidaria, occurring anywhere in the world ocean at depth ranging from the low tide mark to abyssal down to $6000 \mathrm{~m} .{ }^{1}$ Corals provide a habitat for a variety of organisms that humans use for food, including fishes, sea urchins, mollusks, crustaceans and others. Corals can also be classified by into two distinct types; (1) Hermartypic corals which contain zooxanthellae and are responsible for the construction of coral reefs in tropical seas and (2) Ahermartypic corals which have no zooxanthellae and do not form coral reefs. They mostly live in deep water. The northern tropical shallow water areas have the greatest diversity and abundance of hermatypic corals, with the shallow water corals being restricted to the atolls and islands of the Coral Sea (Castro and Huber, 2007). During low spring tides, corals living near the surface may be exposed to strong sunlight which can be deadly. Coral reefs are usually divided into three main categories; (1) Fringing reefs, (2) Barrier reefs and (3) Atolls. The objectives of this research are (a) to know the various types of Montipora species found in present study areas and (b) to study species composition of Montipora in study areas.

\section{Materials and methods}

The present study selected the Genus Montipora; the hard corals which inhabited the Myeik Archipelago water to observe. The living coral samples were collected from five selected stations at Thayawthadangyi Kyun; (1) Taung Pan Gyi (Lat. $12^{\circ} 25^{\prime} \mathrm{N}$ and Long. $98^{\circ} 09^{\prime} \mathrm{E}$ ), (2) Maw Shin (Lat. $12^{\circ} 24^{\prime} \mathrm{N}$ and Long. 98 $08^{\circ} \mathrm{E}$ ), (3) Sha Aw (Lat. $12^{\circ} 15^{\prime} \mathrm{N}$ and Long. $98^{\circ} 05^{\prime} \mathrm{E}$ ) and (4) The Hnit Tan (Lat. $12^{\circ} 17^{\prime} \mathrm{N}$ and Long. $97^{\circ} 57^{\prime} \mathrm{E}$ ). The living coral samples were collected once two months during the spring tide. The coral samples were mainly collected by snorkeling in the shallow water and with the help of local divers who were supplied with air-compressor in deeper water. Besides diving the samples were also collected by hand in the intertidal zone during low tide. The detail morphological characters of all collected specimens were identified under the binocular microscope and followed the methods of Veron and Wallace (1984) and Veron (2000) (Figure 1).

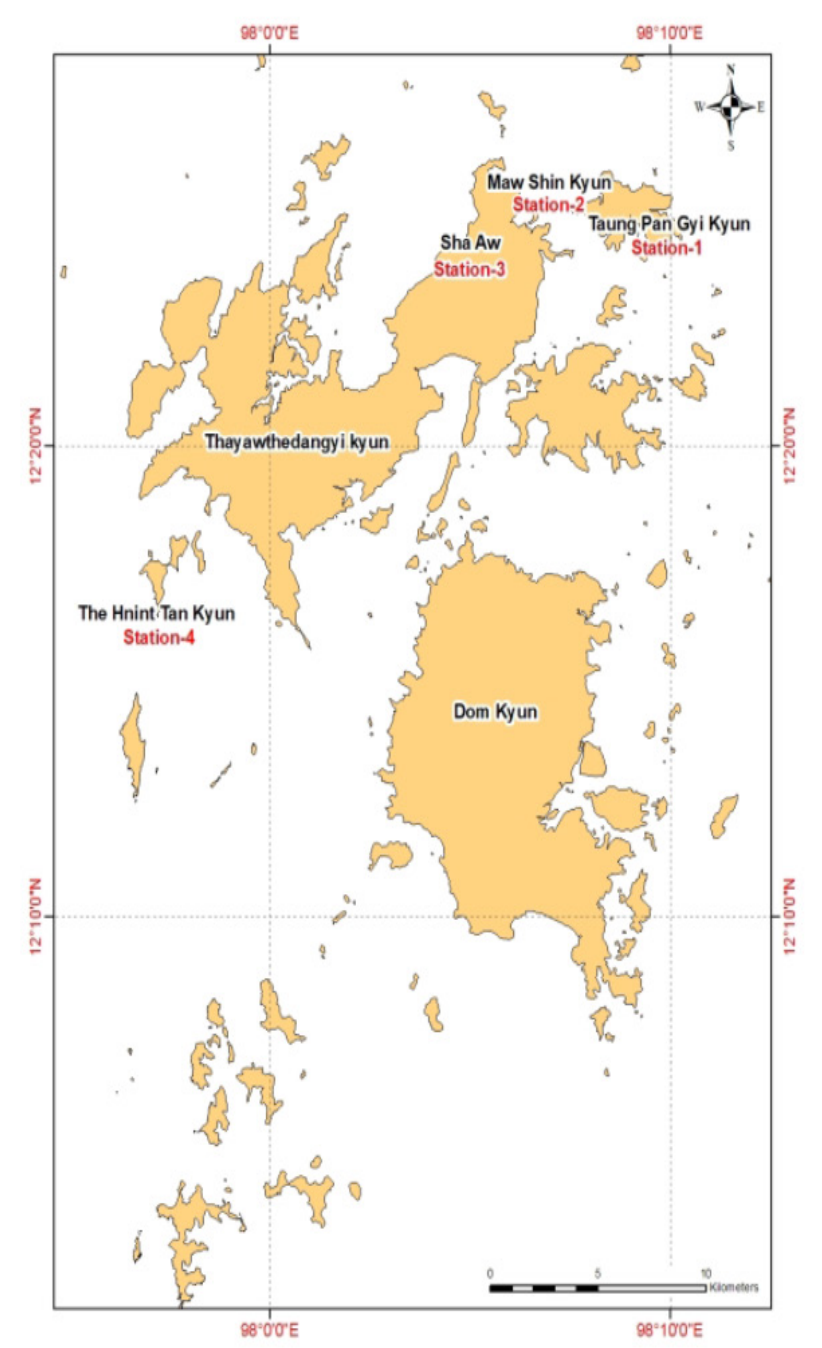

Figure I Map showing the study area. 


\section{Results}

\section{Morphological descriptions of Genus Montipora occurring in the study area}

Phylum- Cnidaria

Class- Anthozoa

Sub-class- Zoantharia

Order- Scleractinia

Family- Acroporidae

Genus- Montipora

Artificial Key to the species of Montipora occurring in the present study area.

1a.Colony dominated by branching growth form.................. 2

1b.Colony dominated by laminar growth form ....................

2a.Corallites not in pitted Montipora digitata

2b.Corallites deeply in pitted ............................ porites

3a.Colonies are not encrusting ..............................patula

3b.Colonies are encrusting ........................................ 4

4a. Corallites indistinct ............................. flabellate

4b.Corallites distinct ......................................

5a.Corallitesare exserttoimmersed....................aequituberculata

5b.Corallites are immersed .............................6

6a.Corallites are immersed, distinguishable theca............ floweri

6b.Corallites are immersed, no theca

M. foliosa

\section{Montipora aequituberculata Bernard, 1897(Figure 2A-2D)}

References: Veron and Wallace, 1984: 114, fig. 300-311; Veron; 2000:76.

Type locality: Albany Passage and Great Barrier Reef (Veron and Wallace 1984)

Synonymy: Montipora amplectens Benard, 1897; Montipora ellisi Bernard, 1897; Montipora erythraea Marenzeller; Crossland, 1952; Stephenson and Wells, 1955; Umbgrove, 1939; Marenzeller, 1907; Montipora composita Crossland, 1952; Wells, 1954; Pillai, 1967b; Scheer and Pillai, 1974 (as cited in Veron and Wallace 1984).

Diagnostic characters: Colonies are foliose, composed of thin, expanding, and flat to contorted laminae, usually with a side attachment and oblique overlapping whorls. The epitheca is inconspicuous or absent. Calices are $0.5-0.8 \mathrm{~mm}$ in diameter. Corallites are small, exert to immersed and are surrounded by thecal papillae.

Septa consist of non-tapered spines. Primary septa are up to $2 / 3 R$ and secondary septa are less than $1 / 2 \mathrm{R}$ or often are reduced. Living colonies are dark brown and margins are pale in color.

Materials examined: Taung Pan Gyi (KK0029-0031); The Hnit Tan (KK0032-0034)

\section{Local distribution: Taung Pan Gyi, The Hnit Tan}

Geographical distribution: East African Coast, Persian Gulf, Indian Ocean Region, Red Sea, Indo-West Pacific, North Australia
(Veron 2000). From the Red Sea to the Tuamotu Archipelago (Veron and Wallace, 1984)

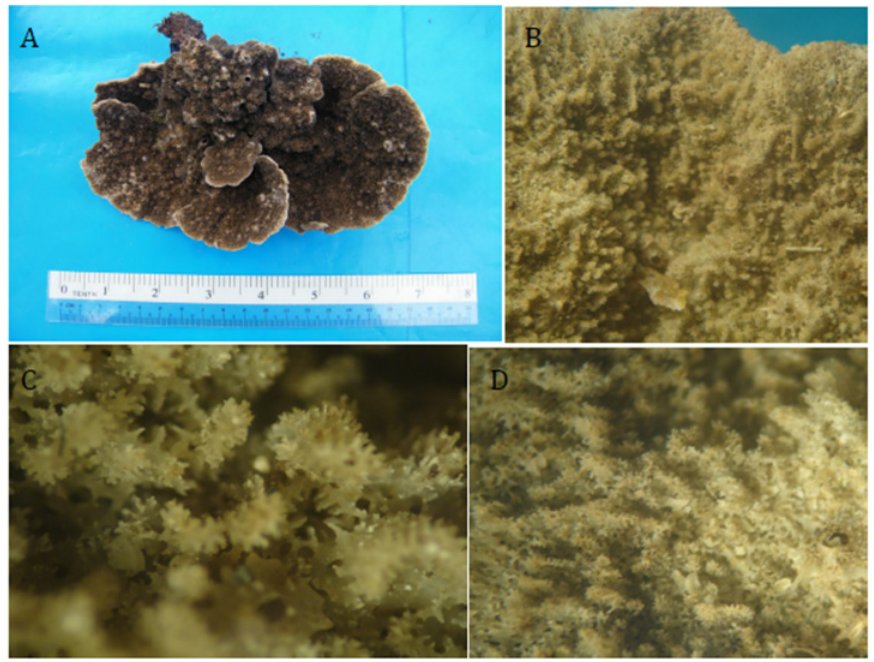

Figure 2A-2D Montipora aequituberculata Bernard:A) Corallum; B) Margin of Corallum; C) Septa and, D) Pappillae.

\section{Montipora digitata Dana, 1846.(Figure 3A-3D)}

References: Veron and Wallace, 1984: 77, fig. 194-206; Veron, 2000:154.

Type locality: Fiji (Veron and Wallace 1984)

Synonymy: Manopora digitata Dana, 1846; Manopora tortuosa Dana, 1846; Montipora tortuosa Dana, 1846; Studer, 1880; Bernard, 1897; Vaughan, 1918; Eguchi, 1938; Montipora rubra (Quoy and Gaimard); Quelch, 1886; Bernard, 1897; Nemenzo, 1967; Montipora poritiformis Verrille, 1869; Bruggemann, 1879a; Montipora divaricata Bruggemann, 1879a; Bernard, 1897; Stephenson and Wells, 1955; Montipora levis Quelch, 1886; Bernard, 1897; Vaughan, 1918; Matthai, 1923; Montipora irregularis Quelch, 1886; Bernard, 1897; Faustino, 1927; Nemenzo, 1967; Montipora fruticosa Bernard, 1897; Crossland, 1952; Seark, 1956; Nemenzo, 1967; Zou, 1975; Montipora marenzelleri Bernard, 1897; Nemenzo, 1967; Montipora indentata Bernard, 1897; Matthai, 1923; Motipora nana Bernard, 1897; Montipora spicata Bernard, 1897; Montipora alcicornis Bernard, 1897; Nemenzo, 1967; Montipora bolsii Bernard, 1897; Montipora spatula Bernard, 1897; Montipora spongilla Bernard, 1900; Montipora ramose Bernard, 1900; Vaughan, 1918; Matthai, 1923; Thiel, 1932; Eguchi, 1938; Crossland, 1952; Ma, 1959; Veron et al., 1974; Montipora compressa Esper; Bernard, 1897; Faustino, 1927; Nemenzo, 1967; Montipora superficialis Bruggemann; Bernard, 1897; Montipora palmata Dana; Bernard, 1897; not Dana, 1896 (as cited in Veron and Wallace, 1984).

Diagnostic characters: Corallum becomes digitate to arborescent with irregularly anastomosing upright branches. Branches are some timed fused into plates. Corallites are small and immersed. They are similar in size and shape. The first septal cycle is complete up to $2 / 3 \mathrm{R}$ and second septal cycle is incomplete up to less than 1/3R. But some corallites are separated by reticulum ridges. The reticulum is fine with spinules having elaborated tips. Reticulum ridges are weakly developed or absent. The coenosteum is smooth. Living colonies are brown in colour. 


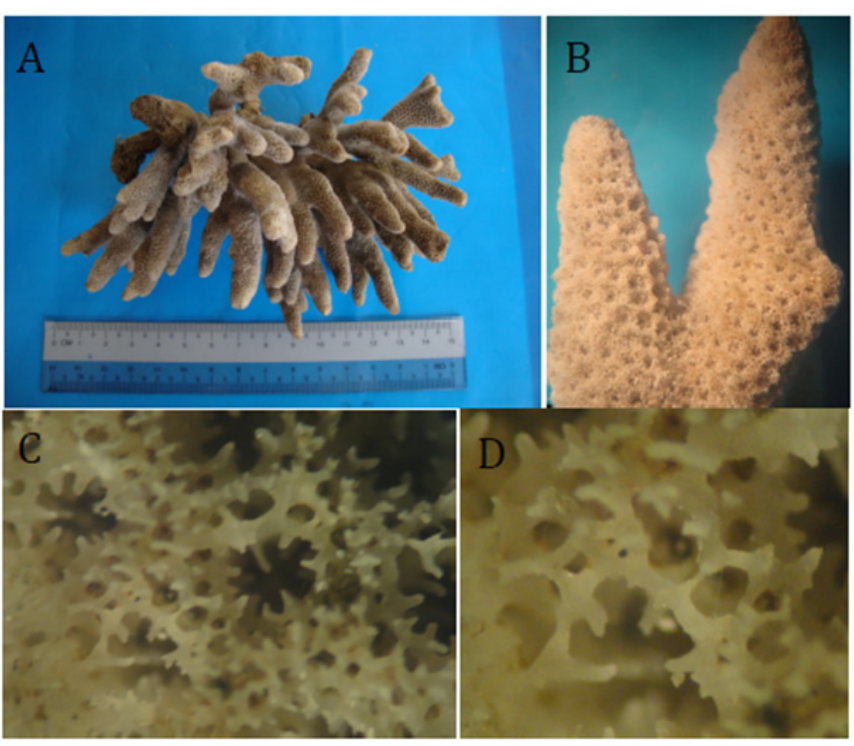

Figure 3A-3D Montipora digitata Dana: A) Corallum; B) Corallite; C) Septa and, D) Coenosteum.

Material examined: Sha Aw (KK0045-0048)

\section{Local distribution: Sha Aw}

Geographical distribution: East African Coast, Indo-West Pacific Region, Red Sea and Indian Ocean Regions (Veron 2000). Throughout the tropical Indo-Pacific, from the western Indian Ocean east to Fiji (Veron and Wallace 1984).

Montipora foliosa Pillas, 1766. (Figure 4A-4C)

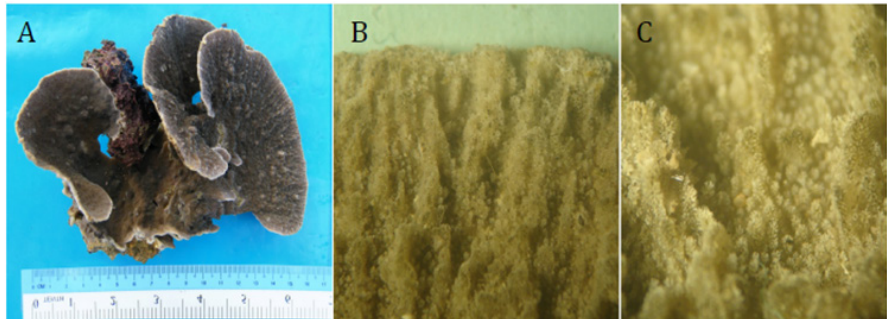

Figure 4A-4C Montipora foliosa Pillas: A) Corallum; B) Margin of Corallum; and, C) Pappillae.

References: Veron and Wallace, 1984: 110, fig. 290-299; Veron, 2000:66.

Type locality - Unknown.

Synonymy: Madrepora foliosa Pallas, 1766; Ellis and Solander, 1786; Agaricia lima Lamark, 1816; Manopora lima Lamark, 1816; Dana,1846; Montipora exesa Verrill, 1869; Quelch, 1886; Montipora lichenoides Verrill, 1869; Montipora Lamarck, 1816; Bruggemann, 1879b; Quelch, 1886; Montipora prolifera Bruggemann, 1879b;

Bernard; 1897; Eguchi, 1938; Crossland, 1952; Seark, 1956; Ma, 1959; Nemenzo, 1967; Montipora minuta Bernard, 1897; Wells, 1954; Stephenson and Wells, 1955; Ma, 1959; Montipora pulcherrina Bernard, 1897; Yabe and Sugiyama, 1935; Ma, 1959; Montipora tubifera Bernard, 1897; Montipora bifronttalis Bernard, 1897;

Montipora circinata Bernard, 1897; Montipora variabilis Bernard, 1897; Ma, 1959; Montipora scutata
Bernard, 1897; Montipora undans Crossland, 1952; Montipora sulcata Crossland, 1952; Montipora rus Bernard, 1897 (as cited in Veron and Wallace 1984).

Diagnostic characters: Corallum is mostly encrusting with horizontal laminae and margins are rounded. Horizontal laminae may be unifacial but epitheca covers most of udersurface, widely-spaced corallites. Corallites are arranged in rows between coenosteum ridges which are conspicuous. Corallites are obviously inclined towards the perimeter on laminate corolla. Corallites are immersed with no the cal development or exsert. Septa are composed of rows of terete spines. The primary septa are up to $1 / 4 \mathrm{R}$ or complete and secondary septa sub-equal to absent. The coenosteum is medium-coarse and spongy except for that of the papillae which is fine and has spinules with elaborated tips. Living colonies are brown in color.

Material examined: Taung Pan Gyi (KK0049-0050); Maw Shin(KK0051-0052)

\section{Local distribution: Taung Pan Gyi, Maw Shin}

Geographical distribution: East Africa Coast, Indian Ocean Region, Red Sea, Persian Gulf and Indo-West Pacific(Veron2000). In the tropical Indo-Pacific, from the Red Sea east to the New Hebrides and Fiji (Veron and Wallace1984).

Montipora flabellata Studer, 1901. (Figure 5A-5C)

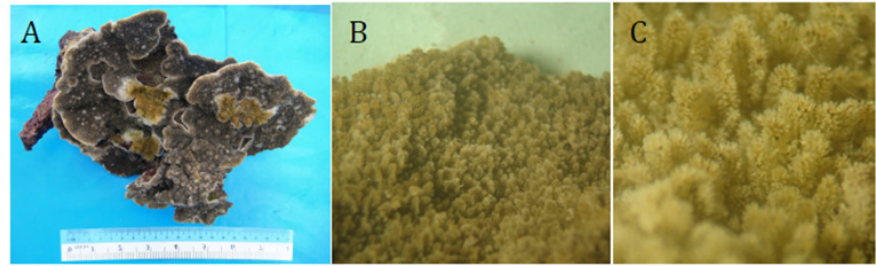

Figure 5A-5C Montipora flabellata Studer: A) Corallum; B) Margin of Corallum; and, C) Pappillae.

References: Veron, 2000: 99.

Type locality: Hawaii (Veron and Wallace 1984)

Diagnostic characters: Corallum is encrusting with irregular lobes. Papillae cover the colony surface and are sometimes fused into ridges. Corallites are small and indistinct. Septa are poorly developed. Colonies are brown or purple.

Materials examined: Taung Pan Gyi (KK0053); Thel Hnit Tan(KK0054-0056)

Local distribution: Taung Pan Gyi, The Hnit Tan

Geographical distribution: Central Pacific and Hawaii Island. (Veron 2000)

Montipora patula Verrill, 1864. (Figure 6A-6C)

References: Veron, 2000: 106

Type locality: Hawaii (Veron and Wallace 1984)

Diagnostic characters: Colonies are thick tiered plates.Plates usually have free edges. Corallites very small, exsert, irregularly spaced and irregular in height. Irregular length of coenosteum papillae are concentrated around the corallites. Septa are very prominent. Colonies are pale tan colour. 
Materials examined: Taung Pan Gyi (KK0060-0061); Maw Shin (KK0062-0065)
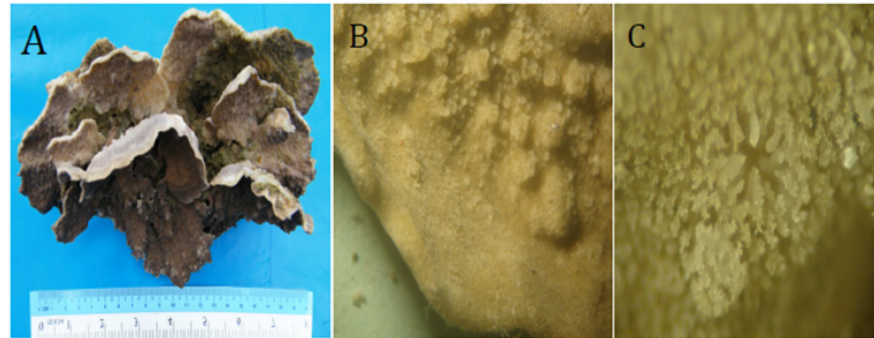

Figure 6A-6C Montipora patula Verrill: A) Corallum; B) Margin of Corallum; and, C) Septa.

Local distribution: Taung Pan Gyi, Maw Shin

Geographical distribution: Central Pacific Ocean, Hawaii Is. $(\text { Veron 2000) })^{2-4}$

Montipora porites Veron, 2000. (Figure 7 A7-D)

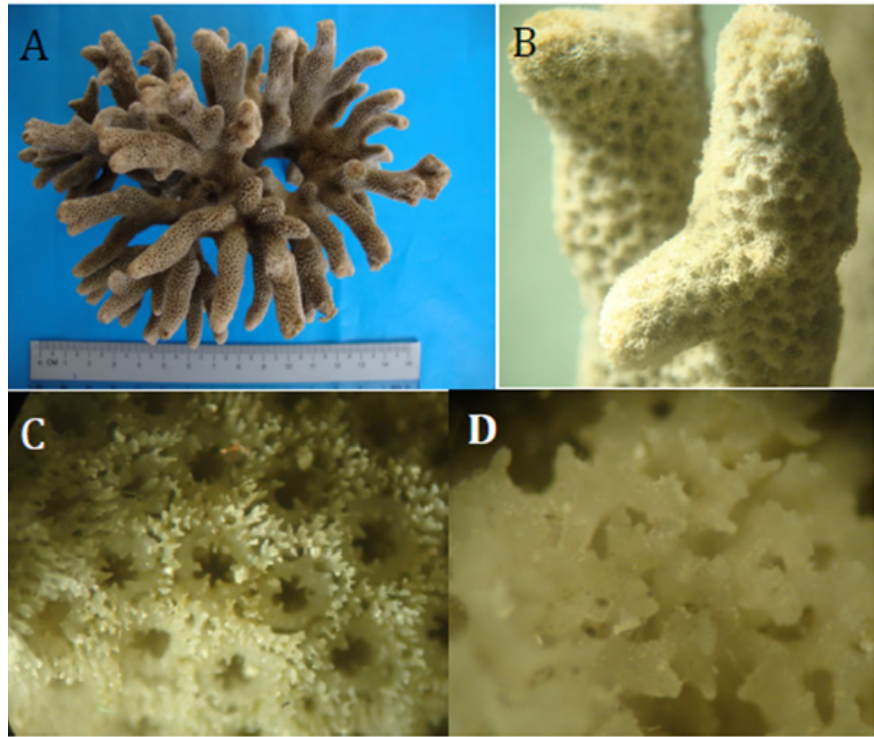

Figure 7A-7D Montipora porites Veron: A) Corallum; B) Corallite; C) Septa and, D) Coenosteum.

References: Veron, 2000: 162

Type locality: Unknown

Diagnostic characters: Colonies are encrusting bases and irregular branches which seldom fuse. Branching may be open or compact. Corallites are deeply embedded between the ridges. The skeletal structure of corallites is porites like, with every elongate septa which occasionally fused. Coenosteum ridges are very prominent and form a sinous pattern over branches surfaces. Grey or green with pale coenosteum ridges.

Material examined: Sha Aw (KK0057-0059)

Local distribution: Sha Aw

Geographical distribution: Indo-China Region, Japan (Veron 2000).

Montipora floweri Wells, 1954.(Figure 8 A-8C)

References: Veron and Wallace, 1984: 24, fig. 29-34; Veron, 2000

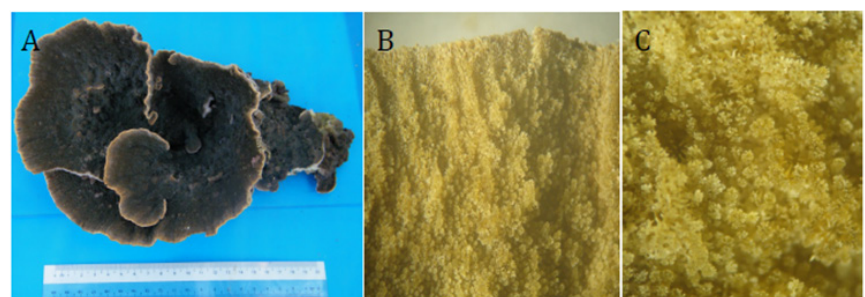

Figure 8A-8C Montipora floweri Wells:A) Corallum;B) Margin of Corallum and, C) Pappillae.

Type locality: Marshall Is. (Veron and Wallace 1984)

Daignostic characters: The corallum consist of sub-massive corollas which have their surfaces covered with irregular fused tuberculate. Septa are in two complete cycles of non-tapered spines, up to $3 / 4 \mathrm{R}$ and

$1 / 2$ R. Primary septa may become thickened in some corallites. The reticulum is medium-coarse and is covered with spinules which may be highly elaborated.

Material examined: The Hnit Tan (KK0231-0235)

Local distribution: The Hnit Tan

Geographical distribution: Marshall Islands (Veron and Wallace 1984) (Table 1) (Figure 9).

Table I The composition of corals species of the Genus Montipora occurred from four stations during the present study

\begin{tabular}{llllll}
\hline Sr. & Species Name & Station & Station & Station & Station \\
No. & & $\mathbf{1}$ & $\mathbf{2}$ & $\mathbf{3}$ & $\mathbf{4}$ \\
\hline 1 & Montipora & + & - & - & + \\
& $\begin{array}{l}\text { aequituberculata } \\
2\end{array}$ & & & & \\
3 & Montipora digitata & - & - & + & - \\
4 & Montipora folisa & + & + & - & - \\
5 & Montipora flabellate & + & - & - & + \\
6 & Montipora patula & - & - & + & - \\
7 & Montipora porites & + & + & - & - \\
& Montipora floweri & - & - & - & + \\
& Total & 4 & 2 & 2 & 3 \\
\hline
\end{tabular}

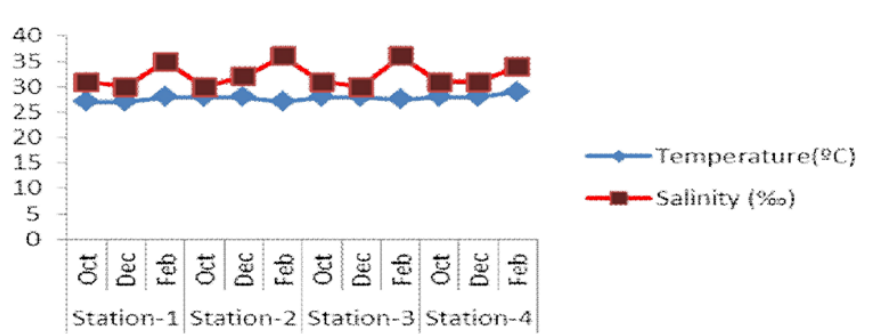

Figure 9 Bimonthly measurements of temperature and salinity from four stations during the present study periods

\section{Discussion}

The present study was conducted at four stations of Myeik Coastal Waters (Thayawthadangyi Kyun and its adjacent islands). Seven coral species of Montipora of the family Acroporidae under Scleractinia were recorded in the present study area. The occurrence of corals species differed insignificantly from one station to each other. M.digitata, M. patula and M. floweri were recorded to be rare throughout the 
study period. A comparison of the environmental parameters such as temperature, salinity and transparency showed different at each station throughout the field study. According to the study, the temperature, salinity and transparency ranged from $27-29^{\circ} \mathrm{C}, 30-36 \%$ and $4.8-$ $5.6 \mathrm{~m}$ respectively. War War Soe ${ }^{5}$ and War War Soe and Htay Aung ${ }^{6}$ observed 3 species of Montipora from Thayawthadangyi Kyun where temperature range was $27.5-30.5^{\circ} \mathrm{C}$ and salinity range was $30-34 \%$. In the present study, 7 species were recorded. The temperature range was $27-29^{\circ} \mathrm{C}$ and salinity range was $30-36 \%$. The environmental parameter was insignificantly different. So, the species composition insignificantly differed between the present study and the previous study. Similarity, Cherry Aung ${ }^{7}$ described 3 species of Montipora from Myanmar Coastal Regions especially Rakhine, Ayeyarwaddy and Tanintharyi Coastal Region. Moreover, Cherry Aung $^{8}$ also described forty-five species of Montipora, under Family Acroporidae recorded from 24 islands of Myeik Archipelago Waters. In the present study, only seven species recorded from Thayawthadangyi Kyun and its adjacent islands. The coral growth occurs optimally when water temperature are $25^{\circ} \mathrm{C}$ to $29^{\circ} \mathrm{C}$ and can only tolerate a few degrees less than this range. And corals also need water salinity high, especially $35 \%$ and they prefer water of $40 \%$ salinity such as occurs in the Red Sea (Robin, Petron and Rives, 1987). In the present study, temperature range $27-29^{\circ} \mathrm{C}$ and salinity range $30-36 \%$ were also found similarly. According to the field study period, Montipora was recorded to be less than other coral species especially Acropora, Favia, Favites etc. ${ }^{9}$

\section{Conclusion}

According to present study, some Montipora species occurred in Myeik Coastal Region. Corals help many marine species for nursery ground and shelters from many natural damage and local people. So, if coral species were existed long term, many marine species were abundantly in the future. These results will be benefit for marine fisheries, economic and health for the local populations in the future. It is expected that the present study will be valuable to be used as based line data for future studies.

\section{Acknowledgments}

I am thankful to Dr Aung Myat Kyaw Sein, Acting Rector of Mawlamyine University and Dr Mie Mie Sein and Dr San San Aye
Pro-Rectors of Mawlamyine University, for their encouragement and supports in preparing this work. I am very grateful to Dr San Tha Tun, Professor and Head of the Department of Marine Science, Mawlamyine University, for his permission on this study. I am very grateful to Dr Nang Mya Han, Professor and Head (Retired), Department of Marine Science, Myeik University, for her valuable suggestions and constructive criticisms on this study.

\section{Conflicts of interest}

Author does not have any conflicts of interest.

\section{References}

1. Rajkumar R, Parulekar AH. Biology of Corals and Coral Reefs. In: Gupta RS, Desa E. Editors. The Indian Ocean. A perspective vol.2.Oxford and IBH Publishing CO PVI LTD. 2001; p.467-492.

2. Castro P, Huber ME. Marine Biology. The Mc Graw-Hill Companies.2007. p. 297-322.

3. Veron JEN, Wallace CC. Scleractinia of Eastern Australia. Part V.Australia. 1984. 485 p.

4. Veron JEN. Coral of the world. Australian Institute of Marine Science and CRR Qld Pty Ltd, Australia. 2000. p.66-447.

5. War War Soe. Study on the Status of Coral Communities in Myeik Archipelago with Special Reference to Thayawthadangyi Kyun. Unpublished. M.Res Thesis. Department of Marine Science, Myeik University, Myeik, Myanmar. 2008.

6. War War Soe, Htay Aung. Hard Corals Composition and Diversity on Coral Reefs surrounding the Thayawthadangyi Kyun in the North of Myeik Archipelago. J Myan Acad Arts and Sc. 7(5):2009;415-447.

7. Cherry Aung. Distribution of Corals in Coastal Zone of Myanmar. $J$ Myan Acad Arts and Sc. 7(5):2009; p.450-460.

8. Cherry Aung. Systematics and distribution of the hard corals (Cnidaria; Hydozoa and Scleractinia) in Myeik Archipelago Coastal Zone. Unpublished. Ph.D. Dissertation. Department of Marine Science, Mawlamyine University, Mawlamyine, Myanmar. 2009b.

9. Robin B, Petron C and Rives C. Living Corals. Singapore. 1987. 144 p. 